\title{
LITERATURA SURDA E ENSINO FUNDAMENTAL: RESGATES CULTURAIS A PARTIR DE UM MODELO TRADUTÓRIO COM ESPECIFICIDADES VISUAIS
}

\author{
Vanessa Regina de Oliveira Martins* \\ Guilherme Silva de Oliveira**
}

RESUMO: O presente trabalho versará sobre a descrição do que é literatura surda a partir de uma revisáo bibliográfica da literatura infantil e dos trabalhos específicos em torno da pedagogia visual, no campo específico da surdez. Faremos, além disso, uma reflexão sobre o trabalho tradutório de uma obra literária do autor Ziraldo Alves Pinto para alunos surdos do ensino fundamental I, de uma escola da rede municipal de Campinas, que está engajada em um projeto de educação bilíngue para surdos. O trabalho tradutório foi realizado por um educador surdo que faz parte da equipe da escola bilíngue. Foram gravados recontos da obra pelos alunos surdos, e a partir das narrativas produzidas, em Libras - Língua brasileira de sinais - fizemos alguns levantamentos sobre leitura, intervenção e criação.

Palavras-chave: Revisão da literatura surda. Pedagogia visual. Pedagogia surda. Surdez.

\section{DEAF LITERATURE AND PRIMARY SCHOOL: CULTURAL RECOVERIES FROM A TRANSLATION MODEL WITH VISUAL SPECIFICITIES}

ABSTRACT: The present work will concentrate on the description of deaf literature, based on a bibliographic review of children's literature in general, and of specific work concerning visual pedagogy, in the specific field of deafness. We will, in addition, reflect on the translation work of a literary piece for elementary education deaf students, by the author Ziraldo Alves Pinto, in a school in the municipal system of Campinas (in the State of São Paulo), which is engaged in a project of bilingual education for the deaf. The translation work was performed by a deaf educator that is part of the team of the bilingual school. The narrative (in Libras - the Brazilian sign language) of the translated work by the

\footnotetext{
* Universidade Federal de São Carlos, Departamento de Psicologia. Sáo Carlos, SP., Brasil. E-mail de contato: vanymartins@hotmail.com.

** Universidade Estadual de Campinas, Programa de Pós-graduação em Educação. Campinas, SP., Brasil.
} 
pupils was recorded, and from those narratives we carried out some survey on reading, intervention and creative work.

Keywords: Deaf literature. Visual pedagogy. Deaf pedagogy. Deafness.

\title{
LITTÉRATURE SOURDE ET ENSEIGNEMENT PRIMAIRE: RENAISSANCE CULTURELLE A PARTIR D'UN MODÈLE DE TRADUCTION AVEC CARACTERISTIQUES VISUELLES
}

RÉSUMÉ: Cet article se concentrera sur la description de ce que nous appelons la littérature sourde, on réalise une revue de la littérature pour enfants de manière générale et du travail spécifique autour de la pédagogie visuelle, dans le domaine de la surdité. En plus, on fait une réflexion sur une traduction d'une œuvre littéraire de Ziraldo Alves Pinto pour les apprenants sourds dans une école primaire, une école publique à Campinas, qui est engagée dans un projet d'éducation bilingue pour les sourds. Le travail de traduction a été réalisé par un enseignant sourd de l'école bilingue dont il fait partie. Nous nous sommes tournés vers les nouvelles versions de la traduction de l'œuvre par les apprenants sourds. Avec les histoires produites en Libras (langue des signes brésilienne) produites par des apprenants sourds, nous avons fait quelques études sur la lecture, la création et l'intervention.

Mots-clés: Littérature sourde. Pédagogie visuelle. Pédagogie sourde. Surdité.

\section{Introdução}

\begin{abstract}
A função social da literatura só se faz manifesta na sua genuína possibilidade ali onde a experiência literária do leitor entra no horizonte de expectativas da prática de sua vida, pré-forma sua compreensão de mundo e com isso repercute também em suas formas de comportamento social.
\end{abstract}

Hans Robert Jauss

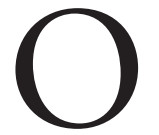

presente trabalho objetiva a reflexão sobre o que é possível pensar, neste momento, e pelas nossas experiências com a educação de surdos, quanto a alguns aspectos sobre a literatura surda. Tal proposta se dá a partir de uma pesquisa realizada no segundo semestre do ano de 2013, com alunos surdos do ensino fundamental I ( $1^{\circ}$ ao $5^{\circ}$ ano $)$, de uma escola municipal no interior de São Paulo. A escola investigada faz parte de um projeto de educação bilíngue municipal, sendo nomeada por escola Polo, por concentrar estudantes surdos e ter 
uma sala multisseriada nos anos iniciais com a Língua brasileira de sinais (Libras) como língua de instrução, contando com professores bilíngues português/Libras. A perspectiva apresentada entende, como na epígrafe trazida, que há uma função social produto dos textos literários e que tal proposta só é conquistada pela relação texto-leitor, quando há um encontro singular do lido com a vida. Portanto, não esperamos que a leitura seja igual para todos ou atinja resultados corpóreos iguais, uma vez que, pelos signos literários há uma relação-acontecimento que é especifica, e assim, de modo único, os desdobramentos também são singulares em cada sujeito. Fazendo um paralelo entre a literatura, a leitura e o aprender, Deleuze (2010) nos ofereceu uma chave de interpretação de que aprender diz respeito a encontros com signos que são lançados - vários signos emitidos cotidianamente $\mathrm{e}$ que nos chegam. É a partir desse encontro que algo corpóreo pode ser produzido, ou seja, pelo corpóreo projeta-se o encontro, e desse acontecimento, "o encontro com o diferente", ocorre a aprendizagem. (DELEUZE, 2010) "Nunca se sabe como uma pessoa aprende; mas, de qualquer forma que aprenda, é sempre por intermédio de signos [...].” (DELEUZE, 2010, p. 21)

Seguindo a proposta acima, a partir da produção de discursos na língua de sinais com um grupo de alunos em sala de aula, lemos coletivamente a obra Quatro estaçóes e um trem doido do autor Ziraldo Alves Pinto. Posteriormente, coletamos dados através da observação, por meio de registros filmados, da interação dos alunos com os materiais produzidos, e ainda, das recontagens feitas a partir da leitura em Libras com a intermediação de um professor surdo - o mesmo autor da tradução do material produzido. A intenção é pensar em aspectos tradutórios da literatura surda que favoreçam a interação e o interesse de alunos surdos dos anos iniciais. Este trabalho pode ajudar a pensar a importância da visualidade e o tipo de tradução específica que precisamos para as atividades com crianças surdas.

Para o momento é de extrema relevância uma reflexão mais apurada de aspectos visuais e tradutórios no âmbito da literatura infantil surda, para pensar como a literatura pode se fazer presente no cotidiano da vida escolar de alunos surdos; e como podemos pensar numa função social da literatura para surdos, como nos alerta a epígrafe de Hans Robert Jauss. Investigamos e investimos num tipo de literatura traduzida de forma culturalmente adaptada com marcas da língua de sinais. (KARNOPP, 2010b) Chamaremos esse trabalho de tradução, o qual será retomado mais à frente, de adaptaçáo cultural por meio da tradução do português para a Libras. São obras que no original estão em língua portuguesa e, para o estudo, foi feita uma adaptação tradutória para a Libras.

Para tal, faremos primeiramente um resgate do que seja a literatura de modo geral e como essa área de conhecimento passou a "existir" dentro da proposta pedagógica como algo da ordem do ensino, de uma cultura, de valores morais, ganhando maior participação e disseminação a chamada literatura erudita, o que supóe o apagamento de muitas outras literaturas populares e, com ela, mui- 
tas culturas. (ZILBERMAN, 2003; FARIA, 2010) Nosso intuito é o de propor um resgate da literatura da diferença, nome que adotamos para conceitualizar a literatura surda por meio de estratégias visuais, com a proposta de uma pedagogia visual ou pedagogia surda. (CAMPELLO, 2007; 2008; LACERDA; SANTOS; CAETANO, 2011)

Faria (2010) descreveu, a partir da obra de Maria Helena Martins (1982), a necessidade de a criança experimentar o gosto pela leitura por meio do contato com a obra, sendo esse o primeiro passo para a produção ou construção do leitor autônomo. Discutiu três modos distintos de apropriação de um texto literário: o sensorial, que se dá por meio do manuseio da obra antes mesmo da criança ser alfabetizada; o emocional, através do seu envolvimento pessoal com a obra, as pontes que o sujeito faz em si perpassado pela leitura; e o racional, no nível mais de interpretação da obra e das marcas textuais deixadas pelo escritor. Não há uma leitura melhor, não sendo, portanto, uma hierarquia, de modo que ao ler ativamos os três níveis de leitura, e, o gosto pela leitura se faz nestes espaços, sejam eles: o do sentir, do experienciar em si, e o das análises feitas de forma mais aprofundada. Tais etapas são importantes na constituição do sujeito leitor. Faria (2010) ainda enfatizou a importância da língua materna e do conhecimento linguístico prévio para a composição do que seja o texto literário e de sua estrutura e funcionalidade.

Desta forma, destacamos a importância da aquisição da língua de sinais desde cedo para um trabalho posterior com a literatura, e ainda, a necessidade de textos em Libras para facilitar o gosto pela leitura em sinais e o envolvimento com a estrutura literária. Por esses caminhos iniciamos nossa andança por meio da literatura e das estratégias visuais que achamos pertinentes para um desenvolvimento mais pleno e inclusivo para alunos surdos, para que seja produzido, primeiramente, o contato com tais textos literários na língua de sinais, e quem sabe esta atividade tradutória de aproximação cultural mova no sujeito surdo um gosto pela leitura em Libras, e porque não, seu interesse pela obra original. Uma atuação que busca uma proposta bilíngue baseada na perspectiva cultural.

\title{
II. Literatura infantil e educação: diálogos possíveis...
}

\author{
[...] atribui-se uma tarefa educativa à literatura infantil, \\ complementar a atividade pedagógica exercida no lar e/ou na \\ escola, o que garante sua necessidade e importância no seio da \\ vida social. (ZILBERMAN, 2003, p.64-65)
}

Pesquisas mostram que há o surgimento da infância num determinado momento histórico, ou seja, não é desde sempre que uma determinada faixa etária representou cuidados maternos e educacionais específicos, por se guardar certas 
especificidades à criança. Para Zilberman (2003, p. 18), a infância passa a ser vislumbrada "[...] como uma certa etapa etária imobilizada num conceito demarcado [...]", e por conta disso veio a ser idealizada e representada por certos conceitos como o de ser o período de desenvolvimento e formação física e comportamental (psíquica), e por isso a necessidade da orientação de um adulto para o bom desenvolvimento - a criança como um pequeno adulto que vive na ignorância social. Sendo assim, e fazendo um resgate histórico, é possível perceber que no ocidente a vida burguesa ascendente fez surgir um centramento ou nucleamento familiar valorizando a vida privada e o individualismo. Deste momento passou a ser interessante o cuidado com a criança e o seu aprendizado das regras sociais e morais. A escola passa a ter um valor específico na vida dos pequeninos que devem aprender o conceito da vida burguesa adulta desde a infância. Se antes disso as crianças já iniciavam responsabilidades dentro dos grupos sociais, agora a infância é guardada como uma fase que requer cuidado e aprendizado da vida cultural adulta e resguardada do trabalho. Como mencionado, está definido o conceito do que se espera da criança e a sua representação no seio social: fragilidade, pureza e com isso, necessariamente, o distanciamento da vida produtiva.

A infância corporifica, a partir de então, dois sonhos do adulto. Primeiramente, encarna o ideal da permanência do primitivo, pois a criança é o bom selvagem, cuja naturalidade é preciso conservar enquanto o ser humano atravessa o período infantil. A consequência é sua marginalização do setor de produção, porque exerce uma atividade inútil do ponto de vista econômico (não traz dinheiro para dentro de casa) e, até mesmo, contraproducente (apenas consome). Em segundo lugar, possibilita a expansão do desejo de superioridade por parte do adulto. (ZILBERMAN, 2003, p. 18-19)

Vê-se, a partir desse ideário produzido, que a literatura surge como condutora ou especificadora de um modelo adulto; como possibilidade de ensino para a criança do modo de vida adulto e fortemente conduzida como ferramenta pedagógica nas práticas de sala de aula. Zilberman (2003) por sua vez faz um destaque para a literatura, e a busca da mesma para além do viés usado na pedagogia, como modalidade da arte, da criação, contendo nela o questionamento do modo de vida imposto por determinada sociedade, em dado momento histórico. Uma reflexão sobre o modo de existência e um apelo à criação. A autora aponta algumas dificuldades uma vez que a literatura infantil, como mencionado, nasce nesta amalgama entre pedagogia, educação e orientação moral. Portanto, cabe o desafio de fazer dela arte e mobilização do pensamento e da criticidade infantil. Trazer a aproximação da literatura, de fato, do gosto infantil, como arte da vida ou arte da existência. (ZILBERMAN, 2003; FOUCAULT, 2010) Desta forma, usada na educação não como condução de um único modo de vida, imposto 
como uma verdade sobre o modo de existência, mas literatura como a construção de múltiplas leituras, que se cria na medida em que se lê, de forma singular, como crítica a um modelo que se quer padronizar, seja para adultos, ou, aqui no caso, para crianças. Seguem algumas reflexóes sobre a literatura infantil e seu status de obra literária:

Com efeito, a caracterização da obra literária evidencia o dilema da literatura infantil. Se esta quer ser literatura, precisa integrar-se ao projeto desafiador próprio a todo o fenômeno artístico. Assim deverá ser interrogadora das normas e, circulação, impulsionando seu leitor a uma postura crítica perante a realidade e dando margem a efetivaçáo dos propósitos da leitura como habilidade humana. Caso contrário, transformar-se-á em objeto pedagógicas, transmitindo a seu recebedor convençôes instituídas, em vez de estimulá-lo a conhecer a circunstância humana que adotou tais padróes. (ZILBERMAN, 2003, p. 176)

Neste sentido trazendo ou promovendo espaço para ruptura de uma objetificação do texto literário, na busca da criticidade, da criação pode ser uma construção de outra forma de exercício pedagógico, ou melhor, possibilita outro diálogo com a educação, numa vertente que discute as relaçóes de poder e saber impostas, questiona o modo de existência posto e traz, para dentro da sala de aula, tensões e não apenas consenso. Enfim, tarefa difícil é trazer para a escola esta arte literária crítica na perspectiva da surdez, isso pela escassez de materiais e pelo não uso, nas escolas, daqueles já existentes. Há que trazer essa literatura menor, no sentido deleuziano (GALO, 2007; 2008), como resistência à maioridade circulante como modelo para verdades. Nesse sentido, essa menoridade surge como empoderamento dos surdos e reverberação de outros saberes e questionamentos que serão construídos pela leitura em Libras; pela visualidade tradutória, não apenas de textos já produzidos, mas de uma literatura que nasce pelas tensóes da própria comunidade surda, inquieta com os modos de manutenção do poder e das amarras à existência singular surda. É assim que se segue o próximo tópico com as discussóes do que concebemos por literatura surda e como podemos usá-la no espaço da escola.

\title{
III. Literatura surda: proposta de uma pedagogia visual
}

\author{
Posso escutar tudo pelos olhos... \\ Posso expressar pelas mãos... \\ Posso sentir os barulhos pelo corpo [...] \\ (Ser Surda, Carilissa Dall'Alba)
}


O que pode ser considerado como literatura surda? Este é um tema que pode ser desdobrado de variadas formas. Primeiramente, apontar o que pode ser considerado literatura surda e, posteriormente, como a literatura, enquanto campo de conhecimento disciplinar pode fazer parte, ou melhor, incluir uma proposta de literatura perpassada por uma pedagogia visual surda, onde as especificidades da surdez são valorizadas e trazidas para o interior da sala de aula. Para isso teremos que aprofundar o que os estudos surdos e as pesquisas, nesta área, têm compilado sobre a pedagogia da visualidade na educação de surdos, tal tema enviesado a partir da semiótica imagética (CAMPELO, 2007), que é considerada como a área de conhecimento que faz uso da língua de sinais, de signos visuais a partir do corpo, do espaço em que flui a corporeidade da língua em sua mais profunda dimensão visual, ou seja, negociar sentidos que se revelam no corpo-língua. Portanto, a semiótica imagética compóe um campo da imagem, da incorporação no ensino de imagens que se configuram no corpo e fazem parte da estrutura da língua de sinais e, por conta disso, deve ser usada como forma de conhecimento linguístico.

Portanto, não é uma mímica sem uma gramática que a componha, mas refere-se ao uso das imagens visuais trazendo-a para dentro da língua de sinais de forma a potencializar a visualidade da língua para os sujeitos surdos. Campelo (2007, p. 106) define de forma bem precisa que a semiótica imagética "[...] é um estudo novo, um novo campo visual onde se insere a cultura surda, a imagem visual dos surdos, os olhares surdos, os recursos visuais e didáticos também [...]".

Retomemos aqui a partilha do conceito de aprender em Deleuze (2010), trazido no início deste artigo. Para o autor o processo singular da aprendizagem só se faz por meio da multiplicidade de emissão de signos que espalhados podem vir a se encontrar no corpo do aprendiz. Portanto, quanto mais signos emitidos maiores as chances dos bons encontros. Para isso a necessidade de um aperfeiçoamento dos signos semióticos lançados para o aluno surdo, nesta vertente da pedagogia visual, só auxiliará ainda mais a aprendizagem, uma vez que mais signos serão lançados para que se faça conhecer pelo surdo, que aprende de modo visual e não auditivo. E é nessa esteira que nos arriscamos a discutir a literatura surda, pela pedagogia da visualidade e, ainda, pela pedagogia surda que afirma a necessidade de um currículo cultural, com temáticas que envolvam a historicidade da surdez. A literatura infantil surda teria traços deste outro currículo que rompe com a normativa de um ensino enviesado para quem ouve - fraturando-o com as especificidades da surdez, promovendo um ensino na diferença.

A expressão "literatura surda" é utilizada no presente texto para histórias que têm a língua de sinais, a identidade e a cultura surda presentes na narrativa. Literatura surda é a produção de textos literários em sinais, que traduz a experiência visual, que entende a surdez como presença de algo e não como falta, que possibilita outras representaçóes de surdos e que considera as 
pessoas surdas como um grupo linguístico e cultural diferente. (KARNOPP, 2010b, p. 161)

Reafirmamos a literatura surda como campo de conhecimento disciplinar importante na medida em que pode ser usada como forma de potencializar a criação e trazer aspectos da cultura surda para dentro da escola. Em Strobel (2008) e Karnopp (2010) podemos perceber como a questão cultural é importante e se faz presente nas obras literárias como forma de disseminação do "jeito surdo", do "modelo de vida surda", num espaço de troca coletiva, sendo uma possibilidade de ampliação cultural, de luta, de compartilhar avanços conquistados, por meio de espaços de negociação discursivos e de construção simbólica, de forma registrada (KARNOPP, 2010):

[...] um ser humano, em contato com o seu espaço cultural, reage, cresce e desenvolve sua identidade, isto significa que os cultivos que fazemos são coletivos e não isolados. A cultura não vem pronta, daí porque ela sempre se modifica e se atualiza, expressando claramente que não surge com o homem sozinho e sim das produçóes coletivas que decorrem do desenvolvimento cultural experimentado por suas geraçôes passadas. (STROBEL, 2008, p. 19)

Após o registro da necessidade de uma pedagogia cultural em que a surdez esteja no bojo da construção curricular, partimos para a definição da literatura surda em seus estudos atuais. Existem três possibilidades de se pensar a literatura surda e seu modo de existência e circulação: as traduçôes, de forma a preservar questóes linguísticas; as adaptaçóes com especificidades culturais, ou seja, com transformações que revelam marcadores culturais da surdez; ou as criaçóes, provenientes das comunidades surdas, sendo produçóes novas ou inovadoras. (MOURÃO, 2012)

A literatura surda é importante para a sistematização e registro cultural, assim como é importante a literatura na vida das pessoas. Neste sentido, citamos Mourão e Silveira (2009, p. 2) sobre este papel:

[...] já se sabe há bastante tempo que a literatura tem poder de influenciar o público que lê, fazendo as pessoas viverem suas histórias e acreditarem nas representaçôes que traz. Mesmo que seja difícil comprovar como os livros produzem opinióes e comportamentos, o fato é que isso acontece com frequência.

Partimos do pressuposto que educadores surdos fazem uma melhor tradução cultural da literatura, sendo parceiros neste trabalho, tanto na produção de materiais, quanto no estudo dos melhores recursos, do espaço, das estratégias 
tradutórias, sendo parte fulcral dentro de uma equipe de pessoas envolvidas no processo tradutório. No exemplo analisado, na produção que será aqui apresentada, optamos pela presença de um tradutor surdo, bem como a sua presença na interlocução com os alunos, na discussão sobre a obra. Notamos que reafirma a potencialidade do surdo, bem como sua imagem como modelo para as crianças surdas. Pensamos se prudente relembrar o que afirmam Sutton-Spence e Quadros (2006, p. 116):

Uma das contribuiçôes principais da poesia sinalizada para o empoderamento do povo surdo é a maneira com que os poemas retratam a experiência das pessoas surdas. [...]. Diante de [...] ameaça à identidade pessoal e cultural dos surdos, os poemas que descrevem e validam a experiência surda são fortemente usados para o empoderamento do povo surdo.

Novamente aqui aparece a literatura como parceira na territorialização da marca da reivindicação, da criticidade em torno das relaçóes de poder, bem como, marcas de uma historicidade de um povo - no caso, são surdos que retratam pela arte de seus corpos formas de entender movimentos políticos vivenciados. As crianças poderão ter acesso a essas formas de pensar e a partir delas produzir novos textos, novas criaçóes. Há inúmeras formas de pensar a expansão da língua de sinais no espaço literário. A criação é uma das formas possíveis dentre as três anunciadas, todavia, em cada uma há que se ver possibilidades de encontros textuais de surdos. Pela tradução se faz textos em língua portuguesa destinados a uma maioria que ouve podendo ser lido na língua de sinais, que bem sabemos não tem o mesmo prestígio das línguas orais. Assim, é uma forma de resistência surda aos modelos centralizadores. As adaptaçóes culturais se tornam espaço de marcar no texto original características de um outro grupo social. Enfim, cada forma literária compóe um mosaico de possibilidades e de diferenças.

\section{Conversas possíveis a partir do trabalho com a literatura no ensino fundamental numa sala bilíngue para surdos}

$\mathrm{O}$ adulto surdo potencializa as expressóes faciais e traz as imagens gráficas dos textos escritos para a língua de sinais, fazendo-as imagens visuais em seu corpo no processo tradutório.

Guilherme Oliveira, Surdo.

Neste tópico abordaremos recortes do projeto realizado em uma das escolas da Prefeitura Municipal de Campinas que tem um trabalho de educação 
bilíngue para surdos, portanto, português e libras são línguas que compóem o cotidiano escolar. Desta experiência faremos a análise de alguns dos resultados observados com o trabalho de tradução para a Libras de uma obra literária estudada em sala. Será uma observação sobre a literatura no espaço da sala de aula e como os alunos surdos se aproximaram do texto literário, na medida em que foi traduzido por um educador surdo para a Libras. Acreditamos que esta é uma proposta que atende a pedagogia visual, uma vez que estamos inserindo no currículo não apenas assuntos relativos a surdez, mas fazendo dele (o currículo) um espaço de resistência, militância e politização no que tange as questôes históricas da surdez. Neste trabalho específico a obra traduzida tem como língua fonte o português, sendo um livro do autor, Ziraldo Alves Pinto - autor estudado durante todo o ano letivo. O livro escolhido foi Quatro Estaçóes e um Trem Doido. Foram realizados três experimentos antes de optar pelo recurso tradutório. Primeiro apresentamos outra obra traduzida para a Libras, não do autor Ziraldo, mas com o intuito de observar se as crianças se relacionavam bem com a leitura. Notamos certa dificuldade na apreensão dos sinais uma vez que o Box em língua de sinais ficava sempre no mesmo espaço da tela na lateral da imagem ilustrativa do livro. As crianças surdas dividiam a atenção na sinalização e nas ilustrações que compunham certamente o todo da obra.

Nossa segunda tentativa fizemos uma tradução do livro do Ziraldo, já conversado previamente, só que sem fundo de imagens da obra. Escolhemos um pano azul e recorremos a algumas imagens que julgamos interessante para a leitura. Evidente que há nisso certo aprisionamento, da nossa parte, do olhar sobre a obra. Enfim, escolhemos uma das professoras bilíngues, fluente em libras, para a sinalização. Notamos que os alunos maiores, do Ciclo II (40 e $5^{\circ}$ ano), conseguiam acompanhar a sinalização, todavia, os menores, do Ciclo I ( $1^{\circ}$ ao $3^{\circ}$ ano), náo seguiam a sinalização e não tinham apoio imagético para a leitura.

\section{Figura 1}

Box em língua de sinais no balão azul apontando para o texto

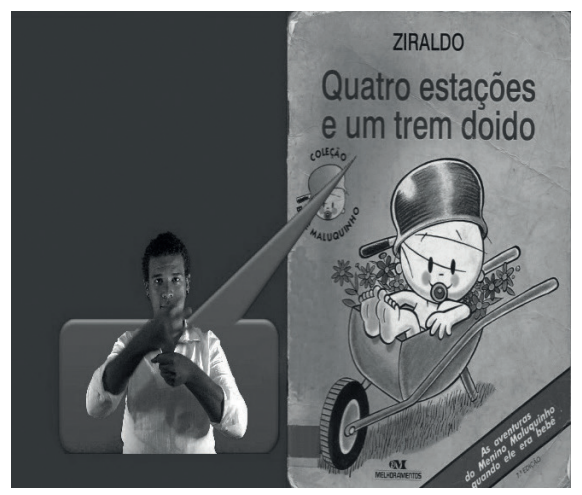


Por fim, adotamos a tradução por meio do uso do box de língua de sinais $^{1}$ (Figura 1) livre no texto, ou seja, aparecendo ao lado do protagonista da cena, de onde estavam os textos escritos. Este recurso facilitou muito a observação da sinalização, bem como, a localização das imagens próximas do tradutor. Outro fator relevante é que o tradutor ficou num tamanho vantajoso em relação a obra, o que facilitou a sinalização.

Ressaltamos que a escolha do fundo azul e do surgimento do tradutor dentro do balão $(B o x)$ com uma espera dada para o início da sinalização, para o aluno ter tempo de explorar o cenário da obra. A tradução foi realizada por um educador surdo que tem contato com as crianças. No entanto, para além do contato e da percepção do adulto surdo, como modelo de leitor para as crianças, o que tornou mais rica a experiência perceber a clareza da tradução, a escolha dos sinais, bem como uso de expressóes faciais e corporais que foram imitadas no reconto pelos alunos. Houve uma simbiose dos leitores surdos com a obra traduzida e isso pode ser capturado nas imagens filmadas do reconto da obra, tanto dos alunos surdos do ciclo I quanto do ciclo II.

A seguir, na Figura 2 e Figura 3, trouxemos recortes da tradução de um trecho da obra e, no reconto, o aluno adota o sinal para o bebê Maluquinho, o mesmo sugerido pelo tradutor, mesmo que tenhamos em sala convencionalizado outro sinal. Há uma apropriação do sinal que é fruto da leitura e da incorporação que o leitor faz dela. Ou seja, fica evidente que a leitura transforma aquele que lê, no sentido do uso dos vocábulos. Vislumbramos isso nas filmagens de recontos.

\section{Figura 2}

Tradução da obra

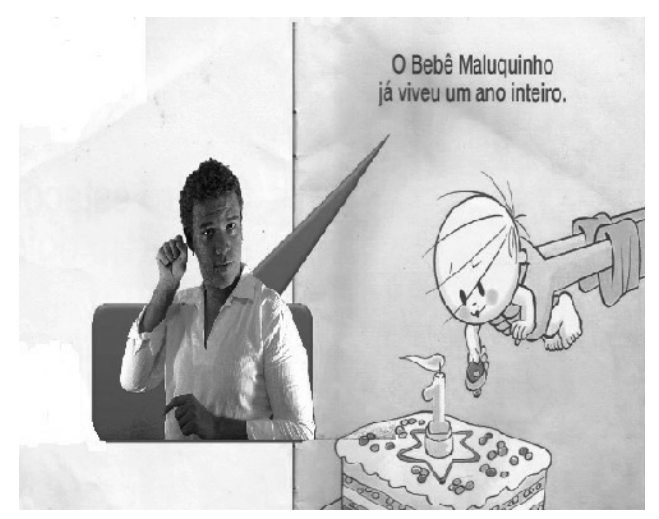




\section{Figura 3}

Reconto pelo aluno J. Ciclo I

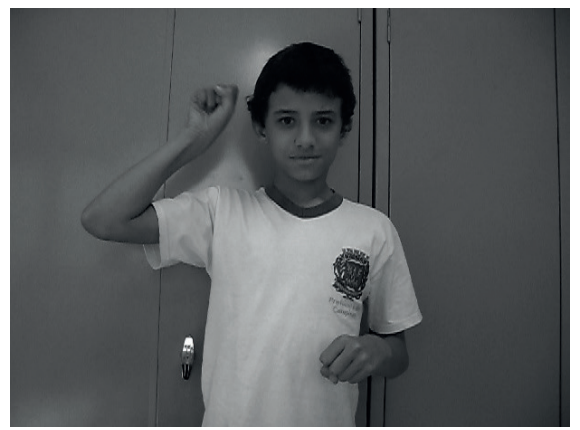

Foi riquíssima a gravação do reconto dos alunos. Usamos as filmagens em sala de aula como meio de contato da escrita da história após a leitura. $\mathrm{O}$ aluno pôde se ver sinalizando, rever sua contação em Libras e só depois arriscar a escrita em português. O primeiro trabalho foi na adequação do texto da Libras. É por meio da Libras que o aluno vai construindo seu texto, com criaçôes, com incorporaçóes, enfim, vai tecendo seu discurso. Na Figura 4 e Figura 5 observa-se o uso de classificadores para marcar a ausência de folhas na árvore. $\mathrm{O}$ tradutor contrai a bochecha tirando todo o ar e com a configuração em L no dorso da mão escorrega-a para reforçar que a árvore estava mesmo seca, sem nenhuma folha. A aluna na Figura 5 repete a cena, porém fazendo na palma da mão (produz a orientação de mão de forma diferente do tradutor), mas imediatamente na Figura 6 corrige-a. Essa correção se dá logo na sequência e por si mesma modifica o lado, ou seja, a orientação da palma da mão, conforme lembra da visualização da história vista.

\section{Figura 4}

Tradução com uso de classificador

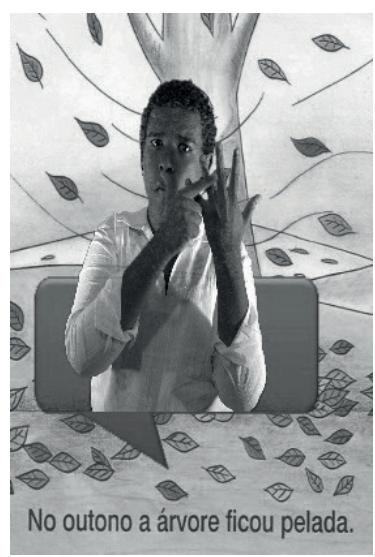




\section{Figura 5}

Primeira sinalização para árvore seca

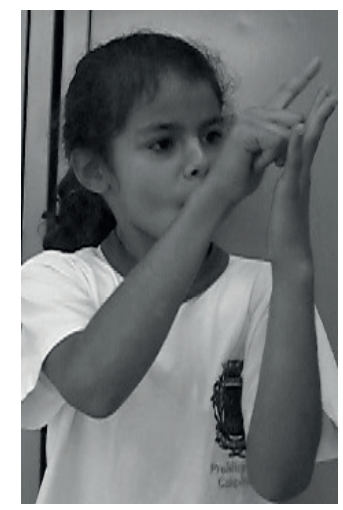

Figura 6

Reconto e correção de G. para uso de classificador

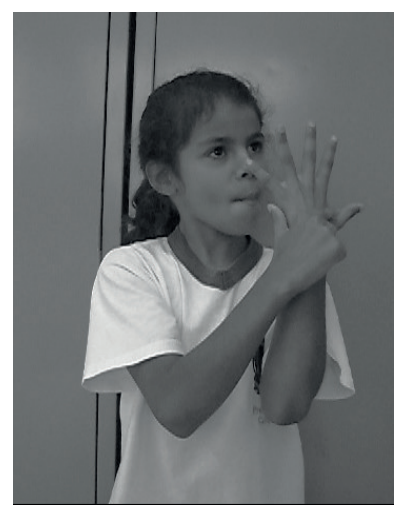

Inferimos disso que há uma relação com o texto traduzido, há leitura, há produção. Os alunos pensam sobre o que leem em Libras e constroem suas narrativas. A aluna G. em sua narrativa demonstra-se presa nas imagens e consegue descrever algumas cenas. $\mathrm{O}$ interessante foi observar que o que mais chamou a atenção da aluna foram as sinalizaçóes que exploravam uso de classificadores na língua de sinais. Notamos dificuldade na apreensão do começo, meio e fim da história, ou seja, a sequência cronológica, mas fica registrada sua produção inicial com um texto em Libras, denotando a necessidade de mais trabalhos como este, de leitura e reconto.

$\mathrm{Na}$ sequência das imagens, que escolhemos para este diálogo, temos a Figura 7 em que o aluno J. também descreve a ausência de folhas da árvore, marcando isso na palma da mão e não no dorso como o tradutor. Notamos que 
o aluno/leitor não para seu texto em Libras para corrigir, a partir do modelo do tradutor surdo, dá andamento e produz uma narrativa com suas intervençóes particulares, todavia, já dominando o conceito do classificador, a temporalidade do texto. Produz uma narrativa mais longa, mais estruturada e com suas marcas pessoais, embora traga muito, no seu reconto, das estratégias tradutórias visualizadas. Essa relação se dá pelo tempo de exposição que este aluno vem tendo à língua de sinais.

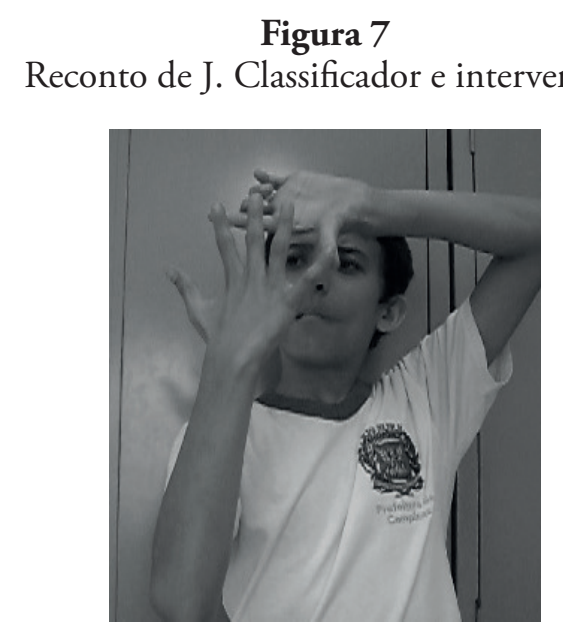

Nota-se na sinalização da aluna G., na Figura 9, uma apropriação do espaço simbólico, da abstração deste espaço e do que faz dele para narrar o uso dos personagens, na marcaçáo de referentes que foi produzida pelo tradutor surdo, como pode ser observado na Figura 8. O espaço e os personagens ficam favoráveis pela disposição imagética que temos na ilustraçáo dos bebês sentados posicionados frente a frente.

\section{Figura 8}

Tradução e marcação de referente

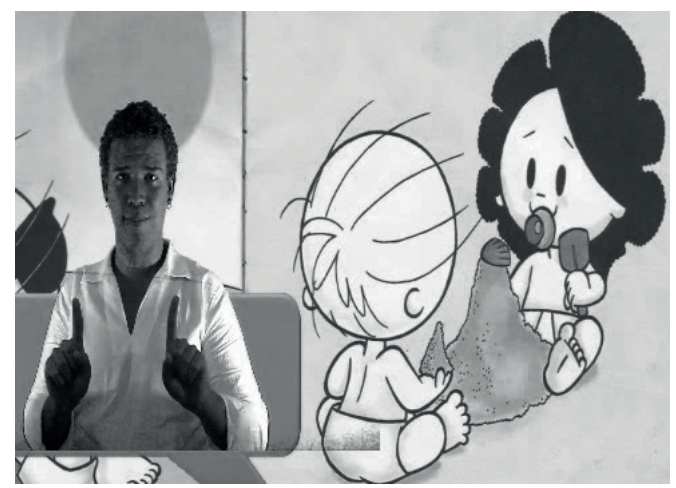




\section{Figura 9}

Reconto de G. com marcação de referente

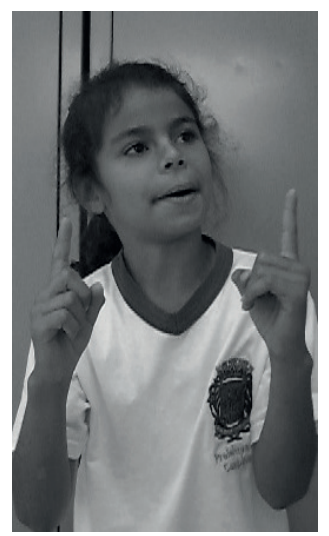

Na figura 10 o aluno J. realiza o sinal do autor Ziraldo que é oferecido no início da tradução. São especificidades tradutórias que vão compondo a ideia de texto produzido, de autoria. Notamos que o aluno do Ciclo II, que já tem um bom domínio da língua de sinais, conseguiu atentar para detalhes mais estruturais do texto, de modo geral. Compôs em sua narrativa quem escreveu a obra, fazendo além da datilologia, o sinal do autor. Trabalhos que mostram um rigor, aprimoramento na sinalização, na visualização dos sinais, que mostram a necessidade de trabalhos textuais com a Libras, ou seja, de produção de vídeos e revisão da sinalização do aluno. O que queremos afirmar é que a literatura surda pode ser uma boa aliada para a disciplina de português como segunda língua, e, para, além disso, tal proposta, mostra como o aluno tem configurado seu discurso: temporalidade, sequência de ideias, incorporação de personagens, uso de espaço, e tantos outros aspectos que podem ser analisados.

\section{Figura 10}

Marcação do autor pelo sinal do Ziraldo

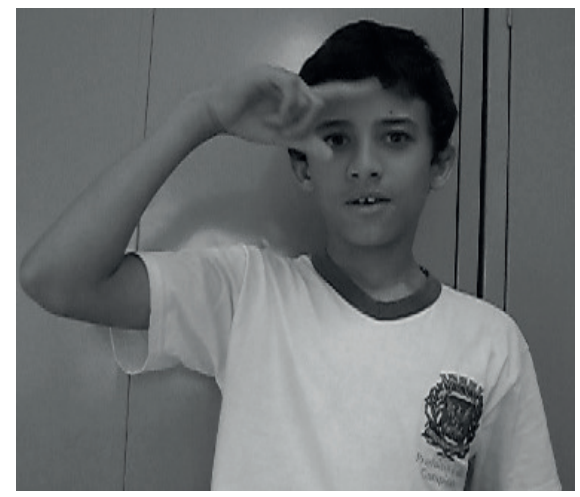


Desta forma, pontuamos a importância da presença do educador surdo como modelo tradutório, bem como do estudo de uma proposta visual surda no campo literário para crianças e, para além da sinalização e da composição com a Libras, há que se pensar nas imagens, no tempo de sinalização. Neste tempo em que a contação para a criança oferece também exploração das imagens trazidas na obra, são os detalhes que aproximam o leitor surdo infantil e características que devem ser mais exploradas para pensar neste público e nesta especificidade literária.

\section{Considerações finais: diálogos finais/iniciais}

É possível, no entanto, encontrar formas de registrar as histórias que traduzam a modalidade visual que os surdos utilizam para narrar suas histórias de vida, piadas, mitos, lendas..., sem perder o movimento que as mãos produzem, as expressóes corporais e faciais que vão construindo e desvendando o enredo, as personagens, o cenário. (KARNOPP, 2010b, p. 161)

Com a visão da possibilidade da manutenção da diferença na escola e sua sistematização ou registro por meio de vídeos, ou seja, com estratégias visuais culturais surdas, propomos o fechamento deste texto e a abertura de novas discussóes sobre a temática: literatura surda e educação. Tema que não temos a pretensão de finalizar ou esgotar as possibilidades de conversa, isto pela necessidade e a vasta amplitude de diálogos a serem ainda travados.

Pensamos na importância cultural da enunciação desta epígrafe trazida aqui, e por nós traduzida, apropriando-se de sua força - por ser um enunciado produzido por uma pesquisadora surda - como forma de diálogo para as consideraçóes de fechamento deste texto: "[...] é possível, no entanto, encontrar formas de registrar as histórias que traduzam a modalidade visual [...]” e se é possível basta a escola se adequar e os sujeitos que dela fazem parte tomarem para si o uso desta modalidade como prática cotidiana. Gravar a narrativa dos surdos alunos e usá-las como material didático é um caminho a ser trilhado, rumo a uma proposta visual, uma pedagogia surda que "escuta" as especificidades daqueles que se fazem sujeito pela visão.

Usar as formas literárias já traduzidas e fazer disso prática em seu planejamento, ou seja, usar vídeos para serem visualizados e estudados pelas crianças, e posteriormente gravar novos vídeos de comentários, de complementação e de contação das histórias assistidas é uma forma pedagógica de manutenção dessa premissa visual que a surdez opera. Uma vez que a língua de sinais é de modalidade visual seu registro deve ser feito por meio de filmagens. Assim, finalizamos 
este texto com uma imensa vontade de manter uma conversa aberta. De pesquisar novas formas de criação e de aquisição da leitura por meio da Libras. De ver como as crianças vão se constituindo leitoras em Libras de histórias diversas, traduzidas, adaptadas ou criadas, mas apropriadas para sua diferença.

\section{Notas}

1. Box de língua de sinais é uma caixa azul de diálogo que abre surgindo a presença do tradutor surdo das cenas da história. Esse nome é usado também para as caixinhas que se alocam no final da tela televisiva, ou em mídias gerais com o intérprete traduzindo os discursos.

\section{Referências}

CAMPELO, A. R. S. Pedagogia visual/ sinal na educação dos surdos. In: QUADROS, R. M.; PERLIN, G. (Orgs). Estudos Surdos II. Petrópolis: Arara Azul, 2007, p. 100-131.

Aspectos da visualidade na educaçáo de Surdos. 2008. Tese (Doutorado em Educação) - Universidade Federal de Santa Catarina, 2008.

DELEUZE, G. Proust e os signos. Rio de Janeiro: Forense Universitária, 2010.

FOUCAULT, M. A hermenêutica do sujeito. Curso dado no Collège de France (1981-1982). São Paulo: Martins Fontes, 2010.

GALLO, S. Acontecimento e Resistência: educação menor no cotidiano da escola. In: CAMARGO, A. M. F.; MARIGUELA, M. (Orgs.). Cotidiano Escolar: Emergência e Invenção. Piracicaba: Jacintha, 2007.

GALLO, S. Deleuze \& a Educação. Belo Horizonte: Autêntica, 2008.

. Produçóes culturais de surdos: análise da literatura surda. Cadernos de Educação. FaE/PPGE/UFPel, Pelotas, v. 36, 2010b, p. 155-174.

KARNOPP, L. Literatura Surda. Curso de Licenciatura e Bacharelado em Letras-Libras na Modalidade a Distância. Universidade Federal de Santa Catarina, 2010.

LACERDA, C. B. F. de; SANTOS, L. F. dos; CAETANO, J. F. Estratégias metodológicas para o ensino de alunos surdos. In: LACERDA. C. B. F. de; SANTOS, L. F. Tenho um aluno surdo, e agora? Introdução à Libras e educação de surdos. São Carlos: EDUFSCar, 2013.

MOURÃO, C. H. N. Adaptação e tradução em literatura surda: a produçáo cultural surda em língua de sinais. ANPED SUL. 9., 2012. Disponível em: < http://www.portalanpedsul. com.br/admin/uploads/2012/Educacao Especial/Trabalho/08 $31 \quad 14$ 3009-7345-1-PB. pdf>. Acesso em: 02/12/2013

STROBEL, K. As imagens do outro sobre a Cultura Surda. Florianópolis: Ed. da UFSC, 2008. 
Literatura surda e ensino fundamental

SUTTON-SPENCE, R.; QUADROS, R. M. Poesia em língua de sinais: traços da identidade surda. In: QUADROS, R. M. (Org.). Estudos Surdos I. Petrópolis, RJ: Arara Azul, 2006.

ZILBERMAN, R. A literatura infantil na escola. São Paulo: Global, 2003.

Recebido em 25 de março de 2014.

Aprovado em 26 de setembro de 2014.

DOI: http://dx.doi.org/10.1590/ES0101-73302015132473 